\title{
Upfront surgery in patients with clinical skip N2 lung cancer based on results of modern radiological examinations
}

\author{
Tomohiro Maniwa ${ }^{1,2}$, Yasushi Shintani ${ }^{3}$, Jiro Okami ${ }^{1}$, Yoshihisa Kadota ${ }^{4}$, Yukiyasu Takeuchi ${ }^{5}$, \\ Koji Takami ${ }^{6}$, Hideoki Yokouchi ${ }^{7}$, Eiji Kurokawa ${ }^{8}$, Ryu Kanzaki ${ }^{3}$, Yasushi Sakamaki ${ }^{9}$, Hiroyuki Shiono ${ }^{10}$, \\ Teruo Iwasaki ${ }^{11}$, Kiyonori Nishioka ${ }^{12}$, Ken Kodama ${ }^{2}$, Meinoshin Okumura ${ }^{3}$; Thoracic Surgery Study \\ Group of Osaka University (TSSGO)
}

\begin{abstract}
${ }^{1}$ Department of General Thoracic Surgery, Osaka International Cancer Center, Osaka, Japan; ${ }^{2}$ Department of Thoracic Surgery, Yao Municipal Hospital, Osaka, Japan; ${ }^{3}$ Department of General Thoracic Surgery, Osaka University Graduate School of Medicine, Osaka, Japan; ${ }^{4}$ Department of Thoracic Surgery, Osaka Habikino Medical Center, Osaka, Japan; ${ }^{5}$ Department of Thoracic Surgery, Toneyama National Hospital, Osaka, Japan; ${ }^{6}$ Department of Thoracic Surgery, Osaka National Hospital, Osaka, Japan; ${ }^{7}$ Department of Thoracic Surgery, Suita Municipal Hospital, Osaka, Japan; ${ }^{8}$ Department of Thoracic Surgery, Minoh City Hospital, Osaka, Japan; ${ }^{9}$ Department of Thoracic Surgery, Osaka Police Hospital, Osaka, Japan; ${ }^{10}$ Department of Thoracic Surgery, Kindai University Nara Hospital, Nara, Japan; ${ }^{11}$ Department of Thoracic Surgery, JCHO Osaka Hospital, Osaka, Japan; ${ }^{12}$ Department of Thoracic Surgery, Kinki Central Hospital, Hyogo, Japan

Contributions: (I) Conception and design: T Maniwa; (II) Administrative support: Y Shintani, K Kodama; (III) Provision of study materials or patients: All authors; (IV) Collection and assembly of data: T Maniwa, Y Shintani, K Kodama; (V) Data analysis and interpretation: T Maniwa; (VI) Manuscript writing: All authors; (VII) Final approval of manuscript: All authors.

Correspondence to: Tomohiro Maniwa. Department of General Thoracic Surgery, Osaka International Cancer Institute, 3-1-69 Otemae, Chuo-ku, Osaka 541-8567, Japan. Email: maniwa-to@mc.pref.osaka.jp.
\end{abstract}

Background: Direct lymphatic drainage from a primary tumor to the right paratracheal or aortic window lymph nodes is often noted in $\mathrm{pN} 2$ disease. This multi-institutional retrospective study investigated the outcomes of upfront surgery in patients with clinical skip N2 disease (N2 disease without N1 disease) and a tumor in the right upper lobe or left upper segment based on results of modern radiological examinations, including positron emission tomography (PET).

Methods: We identified 143 patients with cN2 disease who underwent upfront surgery in 12 institutions under the Thoracic Surgery Study Group of Osaka University between January 2006 and December 2013. Among 143 patients, 94 who underwent PET were analyzed. We classified these patients into Group A ( $\mathrm{n}=39$; clinical skip N2 disease and a tumor in the right upper lobe or left upper segment) and Group B ( $\mathrm{n}=55$; other).

Results: The median follow-up was 56.5 months. Among the 94 patients, 50 (53.2\%) had skip N2 disease and $65(69.1 \%)$ had a tumor in the right upper lobe or left upper segment. The 5 -year overall survival (OS) rates of the 94 patients with $\mathrm{cN} 2$ disease was $47.9 \%$. The 5 -year OS rates for the cN2pN0/1 (n=22) and $\mathrm{cN} 2 \mathrm{pN} 2(\mathrm{n}=70)$ groups were $74.9 \%$ and $41.2 \%$, respectively $(\mathrm{P}=0.034)$. The univariate analysis of OS revealed no significant differences in age, sex, histology, carcinoembryonic antigen (CEA) level, tumor size, PET findings, and number of metastatic lymph nodes when these parameters were dichotomized. A significantly better 5-year OS rate was observed in Group A than in Group B (64.0\% vs. 37.0\%; P=0.039). The multivariate analysis of OS revealed that Group A was a significantly prognostic factor $(\mathrm{P}=0.030)$.

Conclusions: Patients with cN2 disease in Group A had a more favorable prognosis. Upfront surgery may be a treatment option for such selected patients with non-small lung cancer in the specific group.

Keywords: Non-small lung cancer; lymph nodes; survival; surgery; positron emission tomography (PET)

Submitted Aug 04, 2018. Accepted for publication Oct 17, 2018.

doi: $10.21037 /$ jtd.2018.10.115

View this article at: http://dx.doi.org/10.21037/jtd.2018.10.115 


\section{Introduction}

The standard treatment of clinical N2 (cN2) non-small cell lung cancer (NSCLC) is chemoradiotherapy or induction therapy followed by surgery $(1,2)$. However, patients with resectable $\mathrm{N} 2$ disease occasionally undergo upfront surgery (3-5). In fact, a Japanese national database study revealed that 137 patients with $\mathrm{cN} 2$ pathological N2 (pN2) underwent surgery alone, 151 underwent upfront surgery followed by adjuvant chemotherapy, and 108 underwent induction therapy followed by surgery (6). A recent report from the Society of Thoracic Surgeons Database showed that the number of clinical and pathological N2 (cN2pN2) patients who underwent upfront surgery was more than those who underwent induction therapy followed by surgery (7).

Meanwhile, several reports regarding surgery for $\mathrm{pN} 2$ disease have been published (8-10). For instance, direct lymphatic drainage from a primary tumor to the right paratracheal or aortic window lymph nodes is often noted in $\mathrm{pN} 2$ disease $(8,9)$. N2 disease without N1 disease is known as "skip N2" disease. Among patients with pN2 disease, those with skip $\mathrm{N} 2$ disease have a better prognosis than those with N1 and N2 disease (10). However, few studies have been reported on clinical skip N2 disease based on results of modern radiological examinations, including positron emission tomography (PET). In this multi-institutional retrospective study, we investigated the outcomes of upfront surgery in patients with c-skip N2 and a tumor in the right upper lobe or left upper segment based on results of modern radiological examinations.

\section{Methods}

\section{Patients}

In this study, data from 12 different thoracic surgery departments belonging to the Thoracic Surgery Study Group of Osaka University were analyzed. In total, 6,042 patients underwent pulmonary resection for NSCLC between January 2006 and December 2013. The inclusion criteria were as follows: (I) upfront surgery for cN2 NSCLC, (II) lobectomy or pneumonectomy, (III) systematic or lobe-specific lymph node dissection, (IV) cN2 NSCLC diagnosed via computed tomography (CT) and PET, and (V) curative resection. Patients who underwent segmentectomy or wedge resection and those who only underwent lymph node sampling were excluded. In this study, the patients were not necessarily diagnosed with pathological N2 via endobronchial ultrasound-guided transbronchial needle aspiration (EBUS-TBNA) or mediastinoscopy.

All patients with potentially resectable NSCLC underwent CT and PET before surgery. The criterion for lymph node positivity was the shortest nodal diameter of $\geq 10 \mathrm{~mm}$ on CT (11) or a metabolic activity of nodes higher than that of adjacent normal mediastinal and soft tissue on PET (12). Patients with cN2 disease were diagnosed according to each institutional clinical conference or cancer board.

This study was a multi-institutional retrospective one, and operative indications for pulmonary resection were referred to each institution in detail. Whether pulmonary resection was performed through thoracotomy or videoassisted thoracic surgery was decided on a case-to-cases basis and the judgment of the attending physician of each institution. Follow-up varied in this study. However, patient treatment was based on the guidelines for lung cancer stipulated by the Japan Lung Cancer Society. The clinical and pathological stages were determined according to the 7th edition of the Union Internationale Contre le Cancer TNM staging system supported by the International Association for the Study of Lung Cancer (13).

The study protocol was approved by the institutional review boards of all participating hospitals, including that of the Ethics Committee of Osaka University Hospital (No. 16141) and Yao Municipal Hospital (H28-20). Patients were duly informed of the decision-making process for the treatment.

Data on age, sex, smoking index, histology, carcinoembryonic antigen (CEA) (ng/mL), lung disease, cT status, tumor location, standardized uptake value (SUV) on PET, $\mathrm{cN}$ status, preoperative proven $\mathrm{N} 2, \mathrm{pN}$ status, surgical procedure, lymph node dissection, type of resection, epidermal growth factor receptor (EGFR) mutation status, adjuvant chemotherapy, molecular-targeted therapy, and overall survival (OS) were recorded and analyzed. In addition, the following two criteria were used to categorize patients into the specific and nonspecific groups: (I) primary tumor in the right upper lobe or left upper segment and (II) c-skip N2 disease. Thirty-nine patients who fulfilled the two criteria were categorized as the specific group.

\section{Statistical analysis}

Associations among variables were analyzed using $\chi^{2}$ and Student's $t$-tests. OS was defined as the time between the date of pulmonary resection and date of death. To identify 


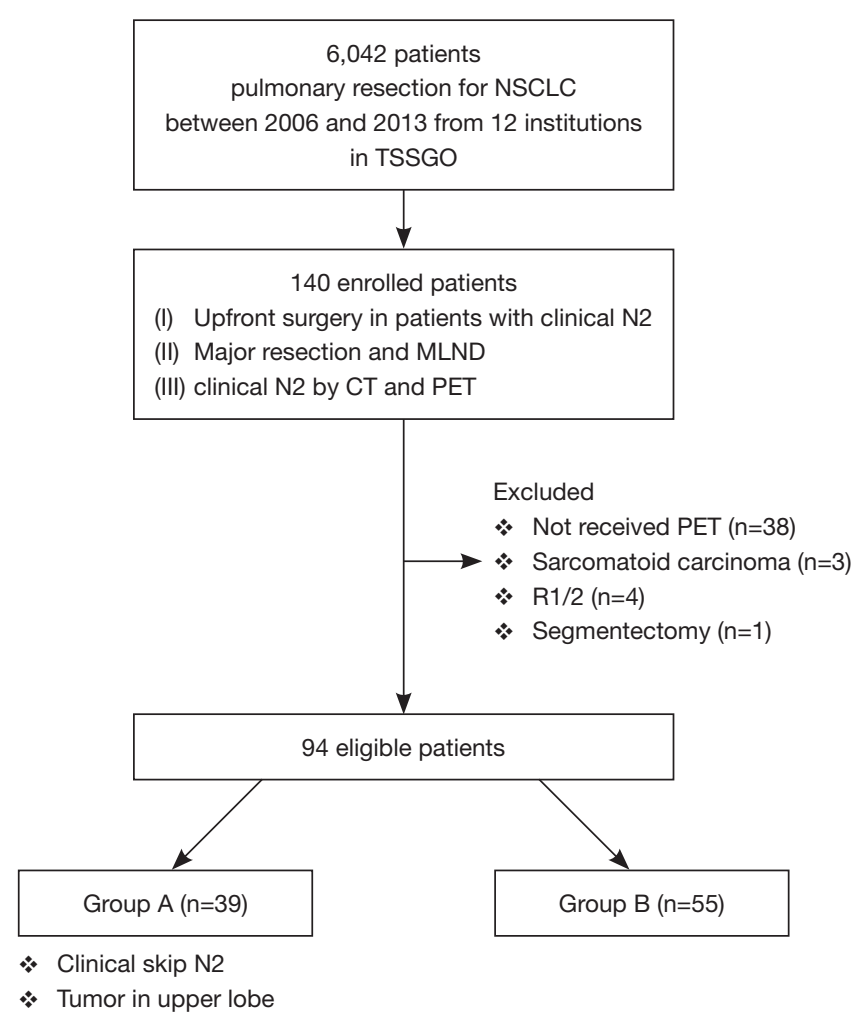

Figure 1 Study design and participants. NSCLC, non-small cell lung cancer; TSSGO, Thoracic Surgery Study Group of Osaka University, Major resection: lobectomy or pneumonectomy; MLND, systematic mediastinal lymph node dissection or lobespecific lymph node dissection.

prognostic factors after pulmonary resection, survival curves and survival rates (i.e., 5-year OS) were estimated using the Kaplan-Meier method. Log-rank tests were used to compare survival across the levels of categorical variables. To counteract the arbitrariness of choosing a threshold and dichotomizing, the effects of continuous variables on survival were also evaluated using Cox proportional hazards models. In multivariate analyses of categoric variables, Cox proportional hazards models with the stepwise selection method were used. All $\mathrm{P}$ values $<0.05$ were considered statistically significant. All statistical analyses were conducted using JMP software, version 9.0 (SAS Institute, Cary, NC, USA).

\section{Results}

Initially, data were obtained for 137 consecutive patients with $\mathrm{cN} 2$ disease who underwent upfront surgery at the
12 institutions. After reviewing the data for eligibility, completeness, and consistency, patients with sarcomatoid carcinoma $(\mathrm{n}=3)$, those who had undergone segmentectomy $(n=1)$, and those who had undergone $\mathrm{R} 1 / \mathrm{R} 2$ resection $(\mathrm{n}=4)$ were excluded. Among the remaining 129 patients, 94 who underwent PET were evaluated (Figure 1).

The median follow-up time was 56.5 (range, 2-110) months. Table 1 shows the characteristics of the 94 patients who underwent upfront surgery for $\mathrm{cN} 2$ disease. The cohort comprised 69 men and 25 women, and the median patient age was 66.5 (range, 35-80) years. In total, 65 patients had adenocarcinoma and 29 had non-adenocarcinoma. The tumor location was categorized as the right upper lobe or left upper segment $(n=65,69.1 \%)$ and others $(n=29,30.9 \%)$. The median diameter of the mediastinal lymph node on CT was 13 (range, 5-30) $\mathrm{mm}$, and the median SUV max of the mediastinal lymph node on PET was 3.9 (range, 1.716.8). Of the 94 patients, 83 (88.3\%) had clinical single N2 disease, $79(84.0 \%)$ had N2 disease mode of lobe-specific spread [17-19], and $50(53.2 \%)$ had N2 disease without N1 (i.e., skip N2 disease). Only two patients were pathologically diagnosed with $\mathrm{N} 2$ via EBUS-TBNA before surgery.

Table 2 shows the surgical procedure, pathological $\mathrm{N}$ status, and postoperative therapy of the patients. In total, 22 patients $(23.4 \%)$ had clinical N2 and pathological N0 or $\mathrm{N} 1(\mathrm{cN} 2 \mathrm{pN} 0 / 1)$ and $70(74.5 \%)$ had $\mathrm{cN} 2 \mathrm{pN} 2$. Of the 70 patients with $\mathrm{cN} 2 \mathrm{pN} 2$ disease, $41(58.6 \%)$ had pathologically single N2 disease, and 39 patients (55.7\%) received adjuvant chemotherapy. Seventeen patients had EGFR mutation and 20 received molecular-targeted therapy throughout survival.

Figure 2 shows OS of all patients who underwent upfront surgery for $\mathrm{cN} 2$. The 5 -year OS rate for patients with $\mathrm{cN} 2$ was $47.9 \%$. Figure 3 shows $\mathrm{OS}$ in the $\mathrm{cN} 2 \mathrm{pN} 0 / 1$ and $\mathrm{cN} 2 \mathrm{pN} 2$ group. The 5 -year OS rates for $\mathrm{cN} 2 \mathrm{pN} 0 / \mathrm{pN} 1$ and $\mathrm{cN} 2 \mathrm{pN} 2$ were $74.9 \%$ and $41.2 \%$, respectively $(\mathrm{P}=0.034)$.

Table 3 shows the results of the univariate analysis of the 5 -year OS for patients who underwent upfront surgery for cN2 disease. No significant differences in age, sex, smoking history, histology, CEA level, tumor size, and clinical lymph node were noted when these parameters were dichotomized, but patients in Group A had a significantly better prognosis than those in Group B ( $\mathrm{P}=0.039)$.

Table 4 shows multivariate analysis using a Cox proportional hazards model. In the multivariate analysis, tumor diameter, CEA level, multiple N2, and histological finding were not significant prognostic factors, but Group A was a significant prognostic factor $(\mathrm{P}=0.030)$. 
Table 1 Characteristics of patients who underwent upfront surgery for N2 disease

\begin{tabular}{|c|c|}
\hline Characteristics & n (\%) \\
\hline Age & 66.5 [35-80] \\
\hline \multicolumn{2}{|l|}{ Sex } \\
\hline Male & $69(73.4)$ \\
\hline Female & $25(26.6)$ \\
\hline \multicolumn{2}{|l|}{ Smoking } \\
\hline Smoker & $76(80.8)$ \\
\hline Non-smoker & $18(19.1)$ \\
\hline Smoking index & $855[0-2,850]$ \\
\hline CEA (ng/mL) & $4.0(0.3-182)$ \\
\hline \multicolumn{2}{|l|}{ Lung disease } \\
\hline Intestinal pneumonia & $12(12.8)$ \\
\hline Emphysema & $19(20.2)$ \\
\hline Tumor diameter & 32 [10-100] \\
\hline Lymph node diameter & 13 [5-30] \\
\hline \multicolumn{2}{|l|}{ SUV max on PET } \\
\hline Tumor & $9.6(2-22.5)$ \\
\hline Lymph node & $3.9(1.7-16.8)$ \\
\hline \multicolumn{2}{|l|}{ Tumor location } \\
\hline RUL & $39(41.5)$ \\
\hline RML & $2(2.1)$ \\
\hline RML & $17(18.3)$ \\
\hline LUL (upper segment) & $25(26.6)$ \\
\hline LUL (lingular segment) & $4(4.3)$ \\
\hline LLL & $7(7.4)$ \\
\hline \multicolumn{2}{|l|}{ cT } \\
\hline cT1a & $9(9.6)$ \\
\hline cT1b & $21(22.3)$ \\
\hline cT2a & $40(42.6)$ \\
\hline cT2b & $13(13.8)$ \\
\hline cT3 & $9(9.6)$ \\
\hline cT4 & $2(2.1)$ \\
\hline \multicolumn{2}{|l|}{ Histology } \\
\hline Ad & $65(69.1)$ \\
\hline Non-ad & $29(30.9)$ \\
\hline
\end{tabular}

Table 1 (continued)
Table 1 (continued)

\begin{tabular}{lc}
\hline Characteristics & $\mathrm{n}(\%)$ \\
\hline Clinical N2 station & $83(88.3)$ \\
Single & $11(11.7)$ \\
Multiple & \\
C-skip N2 & $50(53.2)$ \\
Without N1 & $44(46.8)$ \\
With N1 & \\
Preoperative proven pathological N2 & $2(2.1)$ \\
+ & $92(97.9)$ \\
\hline
\end{tabular}

SUV max on PET, standardized uptake value on positron emission tomography; RUL, right upper lobe; RML, right middle lobe; RLL, right lower lobe; LUL, left upper lobe; LLL, left lower lobe; c-skip N2, clinical N2 disease without N1.

Table 5 shows the comparison data between patients in the specific and nonspecific groups. No significant difference in age, sex, smoking history, histology, CEA level, or tumor size was noted between the two groups. However, the proportion of patients with p-skip N2 disease tended to be higher in the specific group than in the nonspecific group $(\mathrm{P}=0.086)$. No difference in $\mathrm{pN}$ was noted between the two groups.

Figure 4 shows OS in Group A and Group B. The 5-year OS rates for Group A $(n=39)$ and Group B $(n=55)$ were $64.0 \%$ and $37.0 \%$, respectively $(\mathrm{P}=0.039)$.

Figure 5 shows OS of patients who had a tumor in the right upper lobe or left upper segment. The 5 -year OS rates for the c-skip N2 group $(\mathrm{n}=39)$ and non-skip N2 group $(n=25)$ were $64.0 \%$ and $40.1 \%$, respectively $(P=0.26)$.

\section{Discussion}

In this study, we revealed that patients with cN2 disease in the specific group had a more favorable prognosis and that upfront surgery may be a treatment option for such selected patients with NSCLC in the specific group. Patients with cN2 NSCLC have poor survival rates after tumor resection (14-18). Some studies have reported the outcomes of chemotherapy or chemoradiotherapy followed by surgery in a clinical trial setting $(19,20)$; however, the role of surgery in treating $\mathrm{cN} 2$ disease remains controversial. Furthermore, concurrent chemoradiotherapy for stage IIIA NSCLC 
Table 2 Pathological finding and, postoperative course

\begin{tabular}{|c|c|}
\hline Factors & $\mathrm{n}(\%)$ \\
\hline \multicolumn{2}{|l|}{ Surgical procedure } \\
\hline Lobectomy & $85(90.4)$ \\
\hline Bi-Lobectomy & $3(3.2)$ \\
\hline Pneumonectomy & $6(6.4)$ \\
\hline \multicolumn{2}{|l|}{ Lymph node dissection } \\
\hline Lobe-specific lymph node dissection & $12(12.8)$ \\
\hline Systematic lymph node dissection & $82(87.2)$ \\
\hline \multicolumn{2}{|l|}{$\mathrm{pN}$} \\
\hline pNO & $21(22.3)$ \\
\hline $\mathrm{pN} 1$ & $1(1.0)$ \\
\hline pN2 & $70(74.5)$ \\
\hline pN3 & $2(2.1)$ \\
\hline \multicolumn{2}{|l|}{ pN2 station } \\
\hline Single & $41(58.6)$ \\
\hline Multiple & $29(41.4)$ \\
\hline \multicolumn{2}{|l|}{ p-skip N2 } \\
\hline without N1 & $27(38.6)$ \\
\hline with $\mathrm{N} 1(+)$ & $43(61.4)$ \\
\hline \multicolumn{2}{|l|}{ EGFR mutation } \\
\hline+ & $17(18.9)$ \\
\hline- & 45 (47.9) \\
\hline NA & $33(35.1)$ \\
\hline \multicolumn{2}{|l|}{ Adjuvant Cx } \\
\hline+ & $45(47.8)$ \\
\hline CDDP + VNR & 16 \\
\hline CBDCA + PTX & 13 \\
\hline UFT & 6 \\
\hline Others & 10 \\
\hline- & $49(52.2)$ \\
\hline \multicolumn{2}{|l|}{ Receiving molecular targeted therapy } \\
\hline+ & $20(21.3)$ \\
\hline- & 74 (78.7) \\
\hline
\end{tabular}

p-skip N2, pathological N2 disease without N1; NA, not available; CDDP + VNR, Cisplatin + Vinorelbin; CBDCA + PTX, Carboplatin + Paclitaxel; UFT, Uracil-Tegafur; EGFR, epidermal growth factor receptor.

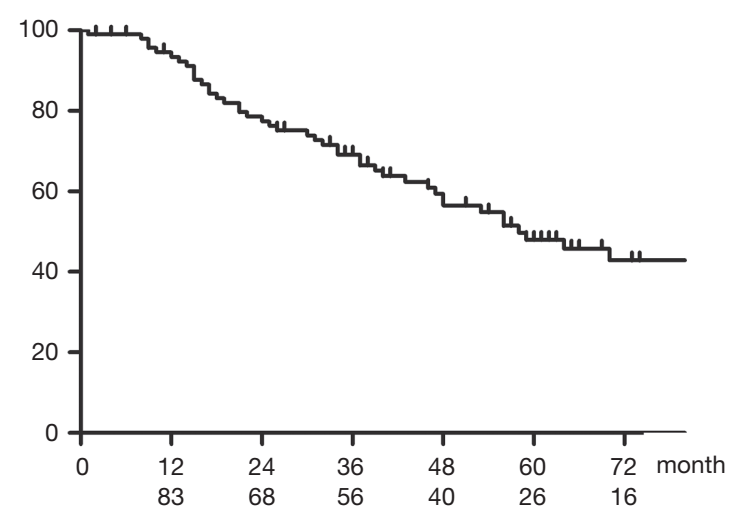

Figure 2 OS in all patients who underwent upfront surgery for cN2. The 5 -year OS rate was $47.9 \%$, and the median OS was 58 months. OS, overall survival.

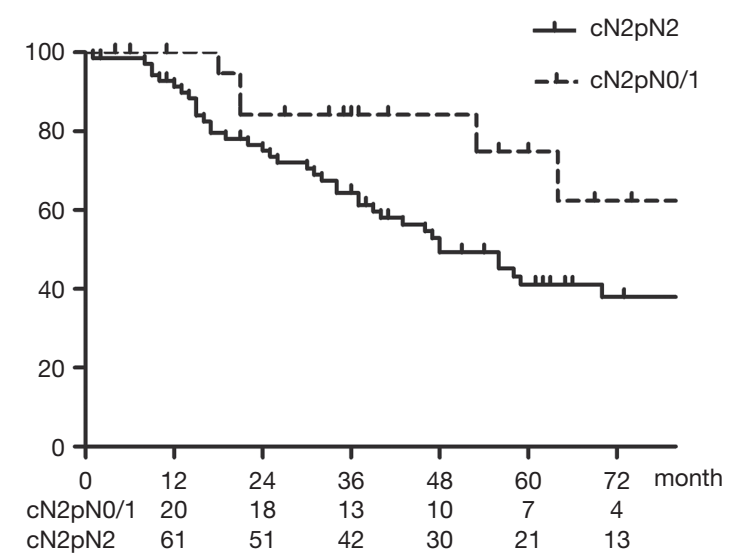

Figure 3 Overall survival (OS) in the $\mathrm{cN} 2 \mathrm{pN} 0 / 1$ and $\mathrm{cN} 2 \mathrm{pN} 2$ groups. The 5 -year OS rates of the $\mathrm{cN} 2 \mathrm{pN} 0 / \mathrm{pN} 1 \quad(\mathrm{n}=22)$ and $\mathrm{cN} 2 \mathrm{pN} 2(\mathrm{n}=70)$ groups were $74.9 \%$ and $41.2 \%$, respectively $(\mathrm{P}=0.034)$. The median OS for patients with $\mathrm{cN} 2 \mathrm{pN} 2$ was 48 months. OS, overall survival.

resulted in an approximately $15-20 \% 5$-year OS $(21,22)$. Based on these results, guidelines in Western countries $(1,2)$ recommend chemoradiotherapy for patients with cN2 stage IIIA NSCLC. Induction therapy followed by surgery is among the treatment options in a clinical trial. However, patients with resectable N2 disease sometimes undergo upfront surgery. In fact, there are several reports on upfront surgery for such patients (3-5). However, no large-scale study has reported whether modern radiologic examinations, including PET, improved treatment outcomes 
Table 3 Univariate analysis of the overall survival for patients who underwent initial surgery for clinical N2 disease

\begin{tabular}{|c|c|c|c|c|}
\hline Variables & $\mathrm{n}$ & 5 year-OS & MST (M) & $P$ value \\
\hline Age & & & & 0.58 \\
\hline $70 \geq$ & 60 & 50.4 & 70 & \\
\hline $70<$ & 34 & 43.7 & 53 & \\
\hline Sex & & & & 0.68 \\
\hline Male & 69 & 47.2 & 56 & \\
\hline Female & 25 & 49.4 & 58 & \\
\hline CEA (ng/mL) & & & & 0.55 \\
\hline$\leq 5$ & 55 & 46.5 & 56 & \\
\hline $5<$ & 39 & 50.6 & 64 & \\
\hline cT & & & & 0.39 \\
\hline cT1 & 30 & 54.0 & 70 & \\
\hline cT2-4 & 64 & 41.8 & 56 & \\
\hline \multicolumn{5}{|l|}{ SUV max on PET } \\
\hline Primary & & & & 0.47 \\
\hline$\leq 9.6$ & 36 & 49.3 & 51 & \\
\hline $9.6<$ & 38 & 49.2 & 56 & \\
\hline No data available & 20 & & & \\
\hline Lymph node & & & & 0.16 \\
\hline$\leq 4.0$ & 35 & 58.8 & 87 & \\
\hline $4.0<$ & 28 & 36.8 & 48 & \\
\hline No data available & 31 & & & \\
\hline Histology & & & & 0.98 \\
\hline Ad & 65 & 46.3 & 56 & \\
\hline Non-Ad & 29 & 52.1 & 87 & \\
\hline cN2 & & & & 0.40 \\
\hline c-single N2 & 81 & 50.3 & 64 & \\
\hline c-multiple N2 & 13 & 35.9 & 53 & \\
\hline Group & & & & 0.039 \\
\hline Group A & 39 & 64.0 & 87 & \\
\hline Group B & 55 & 37.0 & 48 & \\
\hline Surgical procedure & & & & 0.039 \\
\hline Lobectomy & 85 & 50.1 & 64 & \\
\hline Bi-lobectomy & 3 & 66.7 & 87 & \\
\hline Pneumonectomy & 6 & 0 & 26 & \\
\hline
\end{tabular}

Table 3 (continued)
Table 3 (continued)

\begin{tabular}{lcccc}
\hline Variables & $\mathrm{n}$ & 5 year-OS & MST (M) & $\mathrm{P}$ value \\
\hline $\mathrm{pN}$ & & & & 0.034 \\
$\mathrm{pN0}, 1$ & 22 & 74.9 & - & \\
$\mathrm{pN2}$ & 70 & 41.0 & 48 & \\
\hline
\end{tabular}

Group A: primary tumor in right upper lobe or left upper segment, N2 disease without N1; Group B: others. SUV, standardized uptake value; CEA, carcinoembryonic antigen; PET, positron emission tomography.

Table 4 Multivariate analysis of the overall survival using a Cox proportional hazards model for patients who underwent initial surgery for clinical N2 disease

\begin{tabular}{lccc}
\hline Variables & $\mathrm{HR}$ & $95 \% \mathrm{Cl}$ & $\mathrm{P}$ value \\
\hline $\begin{array}{l}\text { Tumor } \\
>3.0 \text { versus } \leq 3.0 \mathrm{~cm}\end{array}$ & 1.42 & $0.73-2.87$ & 0.31 \\
$\begin{array}{l}\text { Single N2 } \\
\text { Multiple N2 versus }\end{array}$ & 1.47 & $0.60-3.28$ & 0.38 \\
$\quad$ single N2 & & & \\
CEA & & & \\
High versus normal & 1.09 & $0.59-2.05$ & 0.78 \\
Histology & & & 0.82 \\
$\quad$ Ad versus Sq & 1.09 & $0.53-2.32$ & \\
$\begin{array}{l}\text { Group } \\
\text { Group B versus Group A }\end{array}$ & 1.99 & $1.06-3.91$ & 0.030 \\
\hline CEA, carcinoembryonic antigen. & &
\end{tabular}

of surgery for $\mathrm{cN} 2$ disease. Thus, we evaluated the current treatment outcomes of upfront surgery for $\mathrm{cN} 2$ disease.

PET has been widely used as a preoperative examination modality for lung cancer in the past decade. This study was designed to assess the treatment outcomes in patients for whom PET was used as a preoperative examination. PET is useful for assessing metastasis of the mediastinal lymph node, and a meta-analysis indicated that the accuracy of PET in diagnosing mediastinal lymph node metastasis ranged from $71 \%$ to $85 \%$ (12). In the present study, the accuracy of PET in detecting mediastinal lymph node metastasis is $74.4 \%$, which is similar to that previously reported. Notably, in terms of patients with cN2pN2 disease, the prevalence $(74.4 \%)$ of pathological N2 disease found in this study was higher than that found in a 
Table 5 The comparison the specific group with the non-specific group

\begin{tabular}{|c|c|c|c|}
\hline Factors & Group A (n=39) & Group B $(n=55)$ & $P$ value \\
\hline Age & 66 [35-79] & 67 [44-80] & 0.94 \\
\hline Sex & & & 0.09 \\
\hline Male & 25 & 44 & \\
\hline Female & 14 & 11 & \\
\hline Smoking & & & 0.32 \\
\hline Smoker & 30 & 46 & \\
\hline Non-smoker & 9 & 8 & \\
\hline Tumor size (mm) & 35 [10-59] & 31 [11-100] & 0.24 \\
\hline LN size (mm) & $14[5-30]$ & 12 [6-30] & 0.74 \\
\hline $\begin{array}{l}\text { SUV max: } \\
\text { primary }\end{array}$ & $9.3(2-22.1)$ & $9.7(2.6-22.5)$ & 0.12 \\
\hline SUV max: LN & $3.4[2-16]$ & $4.0(1.7-16.8)$ & 0.52 \\
\hline Histology & & & 0.98 \\
\hline Ad & 27 & 38 & \\
\hline Non-ad & 12 & 17 & \\
\hline CEA (ng/mL) & $4.1(0.3-90.0)$ & $4.0(0.7-182.0)$ & 0.53 \\
\hline $\mathrm{pN}$ & & & 0.15 \\
\hline $\mathrm{pN} 0,1$ & 12 & 10 & \\
\hline pN2,3 & 27 & 45 & \\
\hline p-skip N2 & & & 0.086 \\
\hline Without N1 & 13 & 14 & \\
\hline With N1 & 12 & 31 & \\
\hline $\mathrm{p}$-single N2 & & & 0.75 \\
\hline $\mathrm{p}$-single N2 & 14 & 27 & \\
\hline p-multiple N2 & 11 & 18 & \\
\hline EGFR mutation & & & 0.50 \\
\hline$(+)$ & 5 & 12 & \\
\hline$(-)$ & 20 & 24 & \\
\hline NA & 14 & 19 & \\
\hline \multicolumn{2}{|c|}{ Adjuvant chemotherapy } & & 0.48 \\
\hline$(+)$ & 17 & 28 & \\
\hline$(-)$ & 22 & 27 & \\
\hline
\end{tabular}

SUV, standardized uptake value; LN, lymph node; CEA, carcinoembryonic antigen.

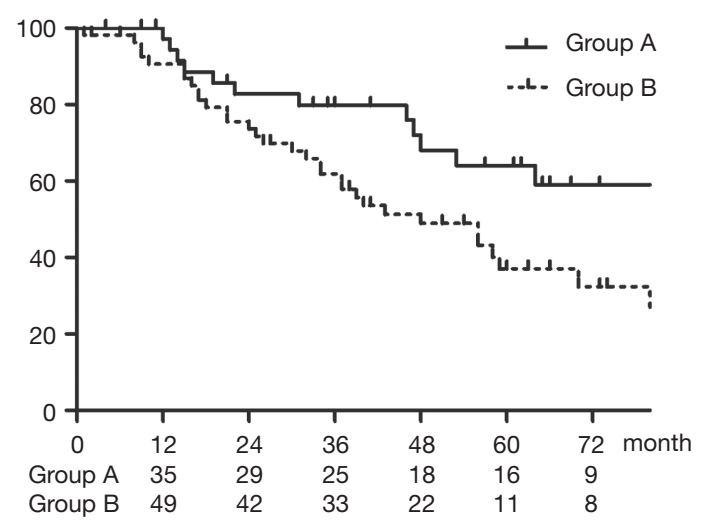

Figure 4 OS in Group A and Group B. The 5-year OS rates of Group A ( $=39)$ and Group B $(n=55)$ groups were $64.0 \%$ and $37.0 \%$, respectively $(\mathrm{P}=0.039)$. The median $\mathrm{OS}$ for patients with cN2 was 87 and 48 months in Group A and Group B groups, respectively. OS, overall survival.

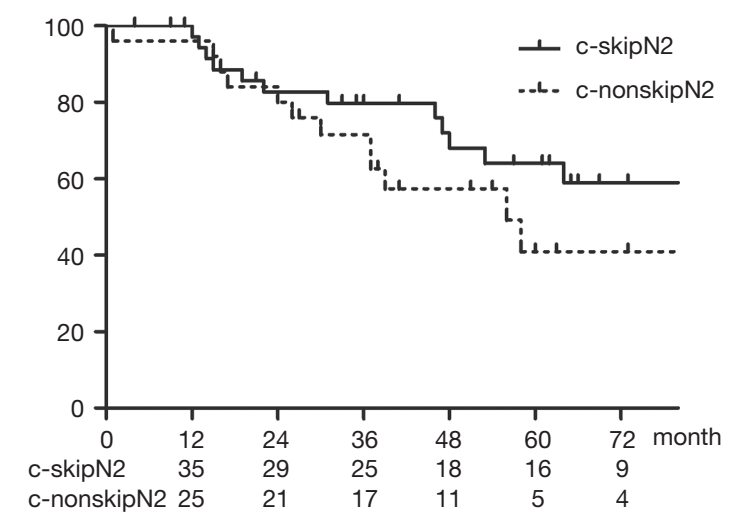

Figure 5 OS of patients who had a tumor in the right upper lobe or left upper segment. The 5-year OS rates for the c-skip N2 group (n=39) and non-skip N2 group (n=25) were $64.0 \%$ and $40.1 \%$, respectively $(\mathrm{P}=0.26)$. OS, overall survival.

previous study (46.3\%) (5). In addition, the prevalence of pathological single $\mathrm{N} 2$ disease in this study was higher than that in previous reports $(4,5,16,17)$. We believe that this result can be attributed to the use of PET as a diagnostic modality in our study.

Several studies have demonstrated that patients with pathological skip N2 have a better prognosis (8-10); however, few reports about clinical skip N2 have been published. In this study, of 44 patients with clinical skip 
N2, 26 (59.1\%) had pathological skip N2. Moreover, of 39 patients in the specific group, 25 (64.1\%) had pathological N2 disease and $13(52.0 \%)$ had pathological skip N2. As a result, the 5 -year OS of patients with $\mathrm{cN} 2$ and $\mathrm{cN} 2 \mathrm{pN} 2$ in the specific group were $64.0 \%$ and $54.5 \%$, respectively.

The prevalence of pathological N2 disease in Group A was higher than that in Group B but the pathological $N$ factor did not differ significantly between the two groups. Univariate analysis for the 5-year OS revealed that patients in Group A had a significantly better prognosis than those in Group B ( $\mathrm{P}=0.039)$. Moreover, multivariate analysis showed that Group A was a significant prognostic factor $(\mathrm{P}=0.030)$. Therefore, we think that our results about upfront surgery for selective $\mathrm{cN} 2$ disease may have considerable importance.

Some studies (23-25) have identified distinct patterns of metastatic spread through the lymphatic pathway, which are dependent on the location of primary tumors. Aokage et al. (24) reported that upper lobe tumors with subcarinal metastasis were also associated with a poor 5-year survival rate of $9.1 \%$. We assume that patients with upper lobe tumors and subcarinal metastasis already have systemic disease. In this study, only 3 patients had upper lobe tumors with subcarinal metastasis; of these patients, 2 had recurrences within 1 year.

Induction therapy has several potential advantages, such as increased tumor sensitivity to chemotherapy, decreased tumor volume to enable better local control after subsequent surgery, rapid eradication of clinically undetected micrometastases, and better tolerance and compliance than postsurgical treatments (26). However, induction therapy also has the disadvantage of increasing the likelihood of postoperative complications. This disadvantage may be negated, however, if initial surgery is performed for patients with $\mathrm{cN} 2$ disease.

Before induction therapy, patients must undergo invasive examinations such as EBUS-TBNA, mediastinoscopy, or video-assisted thoracotomy. The tumors should be pathologically confirmed as N2 disease. However, such invasive examinations are also associated with complications, require additional hospital time, and incur more costs to the patient before surgery (27). In this study, of the 94 patients with cN2 disease, 22 had false-positive N2 disease. If patients with false-positive $\mathrm{N} 2$ received EBUS of the mediastinal lymph nodes, then they might have been identified with $\mathrm{N} 0$ or N1 before surgery.

Immunotherapy, immune check point therapy targeting programmed death receptor ligand (PD-L1), for nonsurgical
NSCLC was effective (28). PD-L1 expression by tumor or immune cells is an important biomarker for predicting treatment response. However, a significant proportion of patients with a diagnosis of lung adenocarcinoma present a heterogeneous staining pattern for PD-L1 (29). Therefore, it is worthwhile to get an entire sample by upfront surgery rather than obtaining a sample by biopsy.

Although multimodality treatment is recommended for patients with N2 disease, such an approach will be difficult for elderly patients or those with a poor performance status. Moreover, patients with interstitial pneumonia or severe emphysema are not eligible for chemoradiotherapy or radiotherapy because of an increased risk for respiratory failure. In clinical practice, high-risk patients should be treated via surgical treatment alone or given the best palliative care. Hence, surgical treatment is sometimes unavoidable for these patients. In the present study, of 70 patients with $\mathrm{cN} 2 \mathrm{pN} 2,11$ (15.7\%) were aged $>75$ years and $25(35.7 \%)$ had severe pulmonary diseases such as emphysema or interstitial pneumonia. As result, only 31 patients $(44.2 \%)$ did not receive adjuvant chemotherapy.

Molecular-targeted therapy for NSCLC has drastically improved patient survival. Among patients with EGFR mutation-positive cancer, those who receive EGFR tyrosine kinase inhibitor had better progression-free survival than those who received standard chemotherapy (30,31). In the present study, 17 (18.9\%) patients had EGFR mutationpositive cancer, and 20 patients $(21.3 \%)$ received moleculartargeted therapy for postoperative recurrence. As shown in Figure 2, this may be associated with the better prognosis observed in this study than those in previous reports.

This study had some limitations that should be considered when interpreting the results. First, this was a retrospective multicenter cohort study, which included various biases. Patient selection bias cannot be excluded, as mentioned previously. Upfront surgery was performed according to the judgment of members of each individual institute, but it was performed following fulfilment of criteria that were based on protocols. Second, no control group with the same background was set for comparison. To clarify the superiority of upfront surgery to standard chemoradiotherapy for patients with specific cN2 disease, a prospective randomized trial is necessary.

\section{Conclusions}

Upfront surgery might be acceptable as a treatment option for selected patients with $\mathrm{cN} 2$ disease. 


\section{Acknowledgements}

None.

\section{Footnote}

Conflicts of Interest: The authors have no conflicts of interest to declare.

Ethical Statement: The study protocol was approved by the institutional review boards of all participating hospitals, including that of the Ethics Committee of Osaka University Hospital (No. 16141) and Yao Municipal Hospital (H28-20). Patients were duly informed of the decision-making process for the treatment.

\section{References}

1. Ramnath N, Dilling TJ, Harris LJ, et al. Treatment of stage III non-small cell lung cancer: Diagnosis and management of lung cancer, 3rd ed: American College of Chest Physicians evidence-based clinical practice guidelines. Chest 2013;143:e314S-40S.

2. Vansteenkiste J, De Ruysscher D, Eberhardt WE, et al. Early and locally advanced non-small-cell lung cancer (NSCLC): ESMO Clinical Practice Guidelines for diagnosis, treatment and follow-up. Ann Oncol 2013;24:vi89-98.

3. Maniwa T, Takahashi S, Isaka M, et al. Outcomes of initial surgery in patients with clinical N2 non-small cell lung cancer who met 4 specific criteria. Surg Today 2016;46:699-704.

4. Matsunaga T, Suzuki K, Takamochi K, et al. Time to refine $\mathrm{N} 2$ staging? $\mathrm{cN} 2 \alpha$ and $\mathrm{cN} 2 \beta$ based on local regional involvement provide a more accurate prognosis in surgically treated IIIA non-small-cell lung cancer than $\mathrm{N} 2$ alone or the number of node stations involved. Eur J Cardiothorac Surg 2014;46:86-91.

5. Hishida T, Yoshida J, Ohe Y, et al. Surgical outcomes after initial surgery for clinical single-station N2 non-small-cell lung cancer. Jpn J Clin Oncol 2014;44:85-92.

6. Yoshino I, Yoshida S, Miyaoka E, et al. Surgical outcome of stage IIIA- cN2/pN2 non-small-cell lung cancer patients in Japanese lung cancer registry study in 2004. J Thorac Oncol 2012;7:850-5.

7. Boffa D, Fernandez FG, Kim S, et al. Surgically managed clinical stage IIIA-clinical N2 lung cancer in The Society of Thoracic Surgeons Database. Ann Thorac Surg
2017; 104:395-403.

8. Inoue $\mathrm{M}$, Sawabata $\mathrm{N}$, Takeda $\mathrm{S}$, et al. Results of surgical intervention for p-stage IIIA (N2) non-small cell lung cancer: acceptable prognosis predicted by complete resection in patients with single $\mathrm{N} 2$ disease with primary tumor in the upper lobe. J Thorac Cardiovasc Surg 2004;127:1100-6.

9. Keller SM, Vangel MG, Wagner H, et al. Eastern Cooperative Oncology Group.Prolonged survival in patients with resected non-small cell lung cancer and single-level N2 disease. J Thorac Cardiovasc Surg 2004;128:130-7.

10. Misthos P, Sepsas E, Athanassiadi K, et al. Skip metastases: analysis of their clinical significance and prognosis in the IIIA stage of non-small cell lung cancer. Eur J Cardiothorac Surg 2004;25:502-8.

11. Glazer GM, Gross BH, Quint LE, et al. Normal mediastinal lymph nodes: number and size according to American Thoracic Society mapping. AJR Am J Roentgenol 1985;144:261-5.

12. Wu Y, Li P, Zhang H, et al. Diagnostic value of fluorine 18 fluorodeoxyglucose positron emission tomography/ computed tomography for the detection of metastases in non-small-cell lung cancer patients. Int J Cancer 2013;132:E37-47.

13. Goldstraw P, Crowley J, Chansky K, et al. International Association for the Study of Lung Cancer International Staging Committee; Participating Institutions. The IASLC Lung Cancer Staging Project: proposals for the revision of the TNM stage groupings in the forthcoming (seventh) edition of the TNM Classification of malignant tumours. J Thorac Oncol 2007;2:706-14.

14. Martini N, Flehinger BJ, Zaman MB, et al. Results of surgical treatment in N2 lung cancer. World J Surg 1981;5:663-6.

15. Pearson FG, DeLarue NC, Ilves R, et al. Significance of positive superior mediastinal nodes identified at mediastinoscopy in patients with resectable cancer of the lung. J Thorac Cardiovasc Surg 1982;83:1-11.

16. Suzuki K, Nagai K, Yoshida J, et al. The prognosis of surgically resected N2 non-small cell lung cancer: the importance of clinical N status. J Thorac Cardiovasc Surg 1999;118:145-53.

17. Andre F, Grunenwald D, Pignon JP, et al. Survival of patients with resected N2 non-small-cell lung cancer: evidence for a subclassification and implications. J Clin Oncol 2000;18:2981-9. 
18. Rosell R, Gómez-Codina J, Camps C, et al. A randomized trial comparing preoperative chemotherapy plus surgery with surgery alone in patients with non-small-cell lung cancer. N Engl J Med 1994;330:153-8.

19. Albain KS, Swann RS, Rusch VW, et al. Radiotherapy plus chemotherapy with or without surgical resection for stage III non-small-cell lung cancer: a phase III randomised controlled trial. Lancet 2009;374:37986.

20. van Meerbeeck JP, Kramer GW, Van Schil PE, et al. Randomized controlled trial of resection versus radiotherapy after induction chemotherapy in stage IIIA-N2 non-small-cell lung cancer. J Natl Cancer Inst 2007;99:442-50.

21. Yamamoto N, Nakagawa K, Nishimura Y, et al. Phase III study comparing second- and third-generation regimens with concurrent thoracic radiotherapy in patients with unresectable stage III non-small-cell lung cancer: West Japan Thoracic Oncology Group WJTOG0105. J Clin Oncol 2010;28:3739-45.

22. Kubota K, Tamura T, Fukuoka M, et al. Phase II study of concurrent chemotherapy and radiotherapy for unresectable stage III non-small-cell lung cancer: longterm follow-up results. Japan Clinical Oncology Group Protocol 8902. Ann Oncol 2000;11:445-50.

23. Okada M, Tsubota N, Yoshimura M, et al. Proposal for reasonable mediastinal lymphadenectomy in bronchogenic carcinomas: role of subcarinal nodes in selective dissection. J Thorac Cardiovasc Surg 1998;116:949-53.

24. Aokage K, Yoshida J, Ishii G, et al. Subcarinal lymph node in upper lobe non-small cell lung cancer patients:

Cite this article as: Maniwa T, Shintani Y, Okami J, Kadota Y, Takeuchi Y, Takami K, Yokouchi H, Kurokawa E, Kanzaki R, Sakamaki Y, Shiono H, Iwasaki T, Nishioka K, Kodama K, Okumura M; Thoracic Surgery Study Group of Osaka University (TSSGO). Upfront surgery in patients with clinical skip N2 lung cancer based on results of modern radiological examinations. J Thorac Dis 2018;10(12):6828-6837. doi: 10.21037/jtd.2018.10.115 is selective lymph node dissection valid? Lung Cancer 2010;70:163-7.

25. Maniwa T, Kodama K. Has lobe-specific nodal dissection for early-stage non-small lung cancer already become standard treatment? J Thorac Dis 2016;8:2407-10.

26. NSCLC Meta-analysis Collaborative Group. Preoperative chemotherapy for non-small-cell lung cancer: a systematic review and meta-analysis of individual participant data. Lancet 2014;383:1561-71.

27. Lim E, McElnay PJ, Rocco G, et al. Invasive mediastinal staging is irrelevant for PET/CT positive N2 lung cancer if the primary tumour and ipsilateral lymph nodes are resectable. Lancet Respir Med 2015;3:e32-3.

28. Reck M, Rodríguez-Abreu D, Robinson AG, et al. Pembrolizumab versus chemotherapy for PD-L1positive non-small-cell lung cancer. N Engl J Med 2016;375:1823-33.

29. Gagné A, Enlow W, Pigeon MA, et al. Comprehensive assessment of PD-L1 staining heterogeneity in pulmonary adenocarcinomas using tissue microarrays: impact of the architecture pattern and the number of cores. Am J Surg Pathol 2018;42:687-94.

30. Maemondo M, Inoue A, Kobayashi K, et al. Gefitinib or chemotherapy for non-small-cell lung cancer with mutated EGFR. N Engl J Med 2010;362:2380-8.

31. Mitsudomi T, Morita S, Yatabe Y, et al. Gefitinib versus cisplatin plus docetaxel in patients with non-small-cell lung cancer harbouring mutations of the epidermal growth factor receptor (WJTOG3405): an open label, randomised phase 3 trial. Lancet Oncol 2010;11:121-8. 